Article

\title{
Car vs. Packaging-A First, Simple (Environmental) Sustainability Assessment of Our Changing Shopping Behaviour
}

\author{
Roland Hischier \\ Empa, Technology \& Society Laboratory, Lerchenfeldstrasse 5, CH-9014 St. Gallen, Switzerland; \\ roland.hischier@empa.ch; Tel.: +41-58-765-7847
}

Received: 18 July 2018; Accepted: 22 August 2018; Published: 28 August 2018

\begin{abstract}
Which way of purchasing your clothes results in the lowest environmental impacts: "running" into the next big city to "plunder" the various clothing stores, or searching through a plethora of online shops and ordering your next shirt directly to you at home? So far, no such comparison has been published. The aim of this study is to get a first basic idea of which of these two consumer choices is the more environmentally sustainable by assessing the potential environmental impacts related to one person's annual purchases of clothing through a simplified life cycle assessment. The study shows that going to a nearby city for shopping is not necessarily worse compared to online purchasing. When a person uses their own car, travel from home to the city and back is responsible for a sizeable amount of the potential impacts. However, the potential impacts of travel are heavily influenced by the means of transport (i.e., use of public transport rather than personal car) and the frequency of shopping excursions over the year. Overall, the potential impacts per single clothing item purchased could be in a similar range for both means of purchase.
\end{abstract}

Keywords: sustainability assessment; life cycle assessment; LCA; online shopping; packaging; mobility; life styles

\section{Introduction}

Zalando-Europe's leading online fashion retailer-currently reports on its website [1] a value of $2.8 \mathrm{~kg} \mathrm{CO} 2$ per parcel delivered in 2016 for their "direct and indirect greenhouse gas emissions in the value chain". Almost half (i.e., $49 \%$ ) of this amount is due to outbound logistics, while only about $16 \%$ is due to the packaging materials themselves. However, the website gives no indication about what this value of $2.8 \mathrm{~kg} \mathrm{CO}_{2}$ per package really means or in what context it should be considered-is this a high value or a low value? What degree of reduction is still possible? etc. Meanwhile, H\&M-the second largest fashion retailer globally with stores in 62 countries-reports in its 2017 Sustainability Report [2] that its sales activities account for about $0 \%$ of their corporate carbon and water footprints. Instead, H\&M shows that the main portions of its carbon and water footprints arise during fabric and yarn production and raw material extraction (e.g., water), respectively. Based on this information, consumers could get the impression that a shopping trip results in a better sustainability performance than ordering a similar article online and get it delivered directly and comfortably at home. But is this really the truth?

One of the key elements of sustainability according to its initial definition in the report from the former Norwegian Prime Minister Gro Brundtland, Our Common Future, in 1987 [3], is its prospective outlook concerning impacts on future generations, and with this, the high relevance of ecological issues. In this area, Life Cycle Assessment (LCA) is a well-established, comprehensive, and rigorous methodology for evaluating the potential environmental consequences of all material, water, 
and energy flows related to a product and/or service over its complete life cycle [4]. It therefore serves as a sound means of evaluating the (environmental) sustainability of goods and service acquisition via alternative means. However, few studies have been published to date that have addressed aspects related to this issue; especially comprehensive studies comparing "traditional" in-store purchasing (including travel) with "modern" online purchasing. A search in SCOPUS with the keyword string "("life cycle assessment" OR "LCA") AND ("e-commerce" OR "online shopping" OR "internet shopping")" over the period 2005 to 2018 returned only eight articles; of which only six are actual case studies that either compare different ways of shopping (online vs. in-store) or investigate online retail activities in more detail.

In their 2006 book chapter, E-commerce, book publishing and retailing logistics, Hendrickson and co-authors used input-output data to compare the potential impacts of the traditional way of purchasing a book in a bookstore with the purchase of the same book online [5]. Regarding global warming, according to this study, online purchasing was found to be advantageous (i.e., causing lower emissions) compared to purchasing at a bookstore. This was mainly due to returns of unsold books from the store; excluding this aspect resulted in almost no difference between the two purchasing options. A similar study is described in the publication from Borggren and co-authors [6], who concluded that "in addition to the paper used, the way books are bought and distributed, including possible personal transportation, can significantly affect the total environmental impact of paper books".

A study from Webber and co-authors [7] compared the impacts of purchasing music via CDs or digital download, concluding that "purchasing music digitally reduces the energy and $\mathrm{CO}_{2}$ emissions associated with delivering music to customers by between $40 \%$ and $80 \%$ from the best-case physical CD delivery". In the frame of a (further) carbon footprint study, Edwards and co-workers compared conventional and online retailing in a more general manner [8]. However, this study is limited to the "last mile", i.e., the journey from a local depot to the home of a customer. In their conclusions, the authors stress that the number of purchased items, the method of travel, and the willingness to group purchases into as few shopping trips as possible (in person as well as online) are identified as determining, critical factors for the resulting carbon footprint. For their 2016 publication, Smidfelt and Winslott examined the consequences on carbon dioxide emissions from passenger transport due to changes in the shopping habits of the Swedish population [9]. According to their calculations, despite the growing population in Sweden, $\mathrm{CO}_{2}$ emissions related to shopping trips in 2030 would likely be about one fifth lower than those in 2012. However, the study focussed on transport-related emissions only.

More broadly, Van Loon and co-workers examined the influence of a variety of factors of online shopping on the overall carbon footprint on online purchasing [10]. However, the study is not comparative in nature, i.e., the carbon footprint of online purchasing is not compared with alternative, traditional means of purchasing the same goods. Rather, the main objective of the study was to inform e-commerce about their improvement potential along the supply chain. The study concludes, similar to the study from Edwards [8], that consumers should reduce complementary shopping trips and maximise the number of items per delivery in order to minimise the negative impacts of their shopping behaviour. Related to this, a recent study conducted in China by Yi and co-workers [11] focussed on one of the consequences of an increase in online shopping, i.e., the increasing prominence of the express (delivery) industry. Their results show that the main impacts lay in the consumption of packaging boxes and their related transportation.

In his master's thesis submitted at EPFL Lausanne, Weideli examined the ecological consequences of US online shopping behaviour through a carbon footprint study [12]. Comparing a total of seven different consumer behaviors-ranging from the "traditional shopper" (going into the shop when searching, when purchasing as well as when returning) to an "impatient cybernaut" (choosing "air fright" as a means of delivery) -Weideli shows that there is around a twofold difference between the lowest and the highest impacts in terms of $\mathrm{CO}_{2}$ (using the purchase of a single toy in an urban area as example; i.e., having travel distances for the traditional shopper limited to $1-8 \mathrm{~km}$ ). Key influencing 
variables were found to be the type of packaging material used for online orders and the distance travelled to the shop for the traditional shopper in the two cases, respectively.

An important element for a lot of people when modelling online purchase activities, although not mentioned as a key factor in any of the studies above, is the information and communication technology (ICT) that is required-i.e., different types of end-user devices (e.g., laptop computers, tablets, or smartphones), as well as the internet and its entire infrastructure. The sustainability of this sector has been covered to a much wider extent in the literature compared to the topic of e-commerce. In the extensive review paper from Subramanian and Yung [13], covering more than 130 scientific LCA publications in the area of consumer electronics, the authors conclude that ICT products are covered more often than other types of consumer electronics and that the most relevant lifecycle stages of these ICT products are most often the production and use phases. In a recently published article, Pihkola and co-workers evaluated the energy consumption of mobile data transfer, based on data from Finland [14]. According to these researchers, despite the clear improvements in the energy efficiency of mobile access networks, the continuously increasing amount of exchanged data together with new functionalities did not result in any energy savings at the Finnish national scale. Rather, the related energy consumption actually increased from 2010 to 2017 by about $10 \%$-despite a substantial decrease in the amount of electricity necessary per gigabyte of transmitted data. Coroama and co-workers showed in a bottom-up study, using transmission data from a 2009 Swiss-Japanese twin conference, a direct energy consumption of internet data flows close to the lowest estimates that could be found in the literature at that moment [15].

Putting these aforementioned data into context, Hischier and co-workers showed in their comparison that the use of the internet infrastructure together with the data centre represents up to $90 \%$ of the total impacts when using mobile ICT devices, such as smart phones or tablet computers [16]; results supported by a similar study in Sweden [17]. Of these impacts that internet use is adding, about half are related to the data centre and its energy consumption [16]. Hence, the choice of the actual energy supply of such a data centre influences the overall impacts of internet usage to a large extent. In this area, the study of Palos-Sanchez and co-workers about the ecological search engine ecosia.org shows one possibility of how an ICT service provider can guide the user towards lower impact choices [18]. However, such kinds of search engines, although positively perceived by users, have not succeeded in forming a high market share, particularly when compared to the market leader, Google, which has an almost $80 \%$ market share [18].

Concerning e-commerce itself, in 2017, about 1.7 billion people used online purchase options, resulting in global e-retail sales in the order of 2.3 trillion US dollars (representing an annual growth rate of almost 25\%); a value that that is foreseen to almost double by 2021 [19]. The penetration rates among different regions, however, are highly variable. In 2016, e-commerce represented less than $2 \%$ of the total retail sales in the Middle East and Africa, while in Asia, it accounted for over 12\% [19]. In Switzerland, according to VSV ASVAD (the Swiss association of e-commerce companies), e-commerce represents close to $8 \%$ of the Swiss retail sales and its annual growth rate is in the order of $10 \%$ [20]. When looking at these most recent statistics on online shopping patterns in Switzerland, published by VSV ASVAD in February 2018 [20], sales of clothing and shoes represented $27 \%$ of total online sales in 2017; the second largest fraction, behind electronic devices $(32 \%)$. Despite this, the environmental performance of online fashion retail in comparison to travel-intensive (shopping) excursions has not yet been studied in great depth. Hence, existing findings cannot be used when evaluating the (ecological) performance of major online shopping retailers (e.g., Zalando) in comparison with a traditional shopping trip to a nearby city (to visit retail shops, such as H\&M). The objective of this study is to get a first basic idea of such a situation-i.e., which consumer (the one travelling into the city for a shopping trip or the one ordering goods on a computer and awaiting their delivery at home) behaves more sustainably. 


\section{Materials and Methods}

In this study, life cycle assessment was used to evaluate the ecological consequences of two different consumer behaviours: online purchase versus in-store purchase. The functional unit considered was defined as "the total purchases of new clothes of one person over the period of one year". The LCA method was applied here in a simplified way, with all calculations made directly with the life cycle impact assessment (LCIA) result retrieved from version 3.4 (recycled-content system model) of the ecoinvent database [21], using Microsoft Excel as a calculation tool. Within the latter, the LCIA results of the various ecoinvent datasets (i.e., the background data of this study) were combined and linked to the foreground system processes for both scenarios (as illustrated in the schema of the here applied system boundaries in Figure 1) and the list of related values used for each scenario (listed in Table 1). Impacts due to the production of clothes were not considered as these would be equivalent in in both cases.

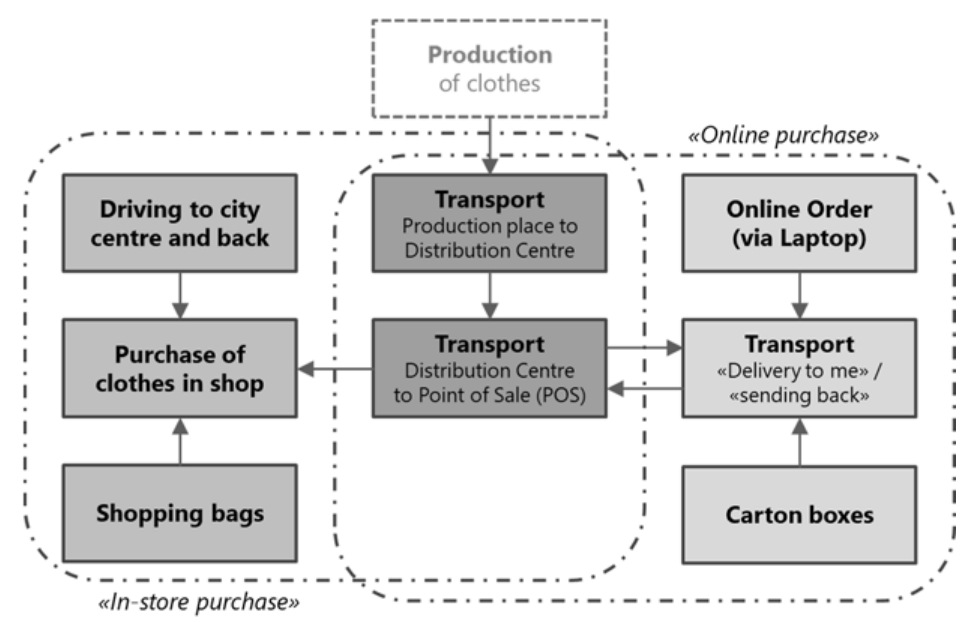

Figure 1. System boundaries of the here examined two different ways (life styles) of shopping for clothes.

Table 1. Key assumptions for the calculation of the basic scenarios for "in-store purchase" (i.e., for case one in Section 3) and "online purchase" (case two in Section 3) in relation to the functional unit-i.e., the purchase of new clothes of one person over a period of one year. For a more detailed list of the key assumptions and their linking with the background data, see Supplementary Materials.

\begin{tabular}{|c|c|c|}
\hline (i) Common Assumptions (for Both Scenarios) & & \\
\hline Transport Production—Distribution & \multicolumn{2}{|c|}{$16,965 \mathrm{~km}$ (split into $96 \%$ boat, $4 \%$ lorry) } \\
\hline Transport Distribution-Point of Sales (POS) & \multicolumn{2}{|c|}{700 km (split into 86\% lorry, 14\% van) } \\
\hline (ii) Specific Assumptions & In-Store Purchase & Online Purchase \\
\hline $\begin{array}{l}\text { Travelling to the City centre (assumed is the } \\
\text { journey Wildhaus-Zürich in Switzerland) }\end{array}$ & $3 \times 170 \mathrm{~km}(4$ persons in car) & - \\
\hline $\begin{array}{l}\text { Active use of ICT device (laptop computer) and } \\
\text { necessary internet infrastructure }\end{array}$ & - & $6 \times 30 \mathrm{~min}$ \\
\hline Number of purchase cloths items & $3 \times 8=24$ & $6 \times 7=42$ \\
\hline Share of clothes on total shopping & $75 \%$ & $100 \%$ \\
\hline Shopping bags & $3 \times 2$ paper bags, $3 \times 2$ plastic bags & - \\
\hline Carton boxes & - & $6 \times 1$ box $(0.82 \mathrm{~kg})$ \\
\hline Transport of "delivery to me" & - & $424 \mathrm{~km}^{1}$ \\
\hline Number of cloths items that are send back & - & $6 \times 3=18$ \\
\hline Transport of "sending back" & - & $350 \mathrm{~km}^{2}$ \\
\hline
\end{tabular}

${ }^{1}$ Split into $40 \%$ lorry, $40 \%$ train, $20 \%$ van; ${ }^{2}$ split into $74 \%$ lorry, $17 \%$ train, $9 \%$ van. 
Three impact categories were considered in this study: Global warming potential (GWP) in $\mathrm{kg} \mathrm{CO}$-equivalents $\left(\mathrm{CO}_{2}\right.$-Eq) [22], the total consumption of fossil energy carriers in the form of the (non-renewable) cumulative energy demand expressed in MJ-Eq, and the overall environmental impact of the examined system expressed in Swiss Eco-points, according to the method of ecological scarcity [23]. In Switzerland, these three impact categories are often used as overall indicators of potential impacts in simplified LCA studies. They represent many of the most relevant environmental issues in society today (GWP, CED), and, through the third factor in particular, a "true and fair view" of the overall potential environmental impacts (at least from the point of view of the Swiss Government, who commissioned the method of ecological scarcity). Hence, these three factors were here considered as being adequate for a simplified environmental sustainability assessment.

\section{Results}

In order to get a clear-but nevertheless structured and comprehensive-overview of this simple assessment of the relative environmental sustainability of different ways of purchasing clothes, the results have been established systematically: firstly, the contributions of different processes/activities to the overall potential impacts of each case are considered; secondly, a comparison of the total potential impacts of each case is made; and thirdly, the influence of several key assumptions and factors (i.e., a sensitivity analysis) on the results of this comparison is presented.

\subsection{Case One-A Shopping Trip to the City (i.e., In-Store Purchase)}

The first scenario represents the potential impacts of a family (two adults, two children) travelling three times per year from Wildhaus to Zürich (both in Switzerland) via a private car for a "shopping day".

Using the values summarised in Table 1 , almost $90 \%$ of the potential environmental impacts are due to the travel to Zürich and back home (i.e., driving with the private car), as shown in Figure 2. This result is independent of the applied LCIA impact category, with all three showing an almost identical distribution. Regarding the remaining $~ 12 \%$ of potential impacts, the CED method shows an almost equal split, while the two other impact categories (GWP, Swiss eco-points) show that the consumption of shopping bags only contributes about one quarter of these remaining impacts $(\sim 3 \%)$.

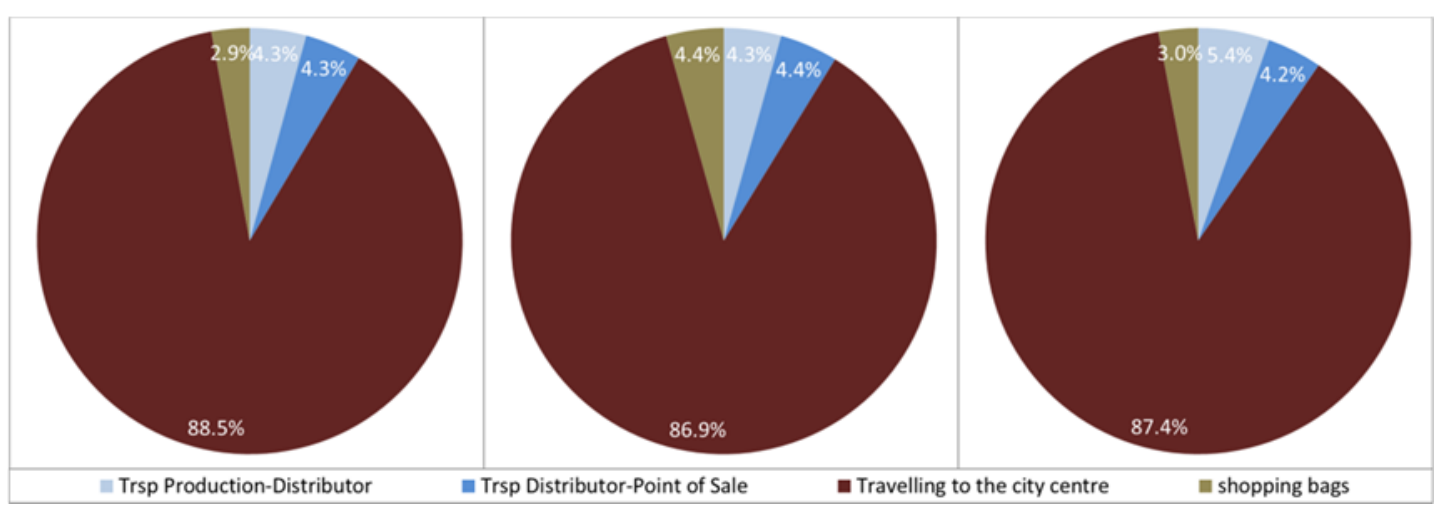

Figure 2. Distribution of the environmental impacts (from left to right-Global Warming Potential in $\mathrm{kg} \mathrm{CO}_{2}-\mathrm{Eq}$, (non-renewable) Cumulative Energy Demand in MJ-Eq, Ecological Scarcity in Swiss Eco-points) per person and year for the in-store purchase, i.e., when travelling for shopping to the next city centre (the key assumptions for this calculation are reported in Table 1).

\subsection{Case Two-Online Purchase}

Nowadays, such a shopping excursion can be replaced by a virtual journey on the web-i.e., all the clothes could be ordered online and then delivered directly to the door. Using the values summarised in Table 1, about one third of the potential impacts are related to the consumption and disposal of carton boxes (used for sending the clothes to the customer and, if subsequently returned, 
back to the retailer), as shown in Figure 3. The use of ICT infrastructure (i.e., the laptop and all the infrastructure of the internet, up to the server farms of online shops) shows the lowest contribution across all LCIA impact categories; never exceeding $5.5 \%$ of the overall potential impacts.

Overall, all the (various) transport steps sum to $61-64 \%$ of the overall potential impact when ordering your clothes online, with three of the transport phases (i.e., place of production to distribution centre, distribution centre to the POS, and the "delivery to me") showing about the same impacts.

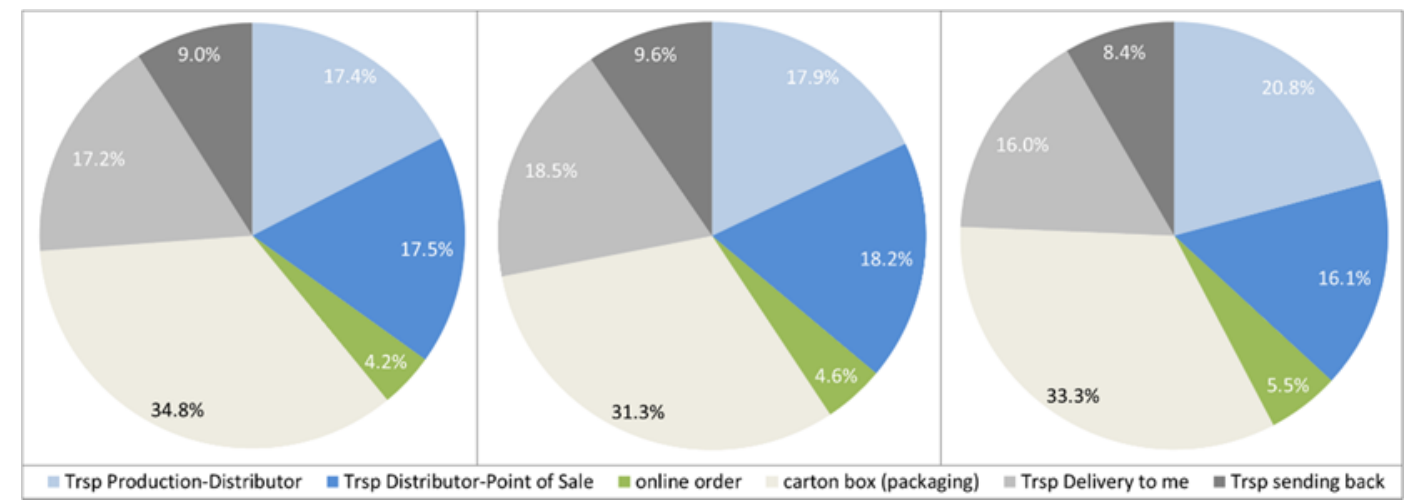

Figure 3. Distribution of the environmental impacts (from left to right-Global Warming Potential in $\mathrm{kg} \mathrm{CO}_{2}$-Eq, (non-renewable) Cumulative Energy Demand in MJ-Eq, Ecological Scarcity in Swiss Eco-points) per person and year resulting from the online purchase of clothes (key assumptions for this calculation are reported in Table 1).

\subsection{Comparision between the Two Scenarios}

A comparison of the results from case one (i.e., going three times a year with the car for a shopping day into the city) and case two (i.e., ordering the equivalent number of pieces of clothes via internet) is shown in Figure 4.

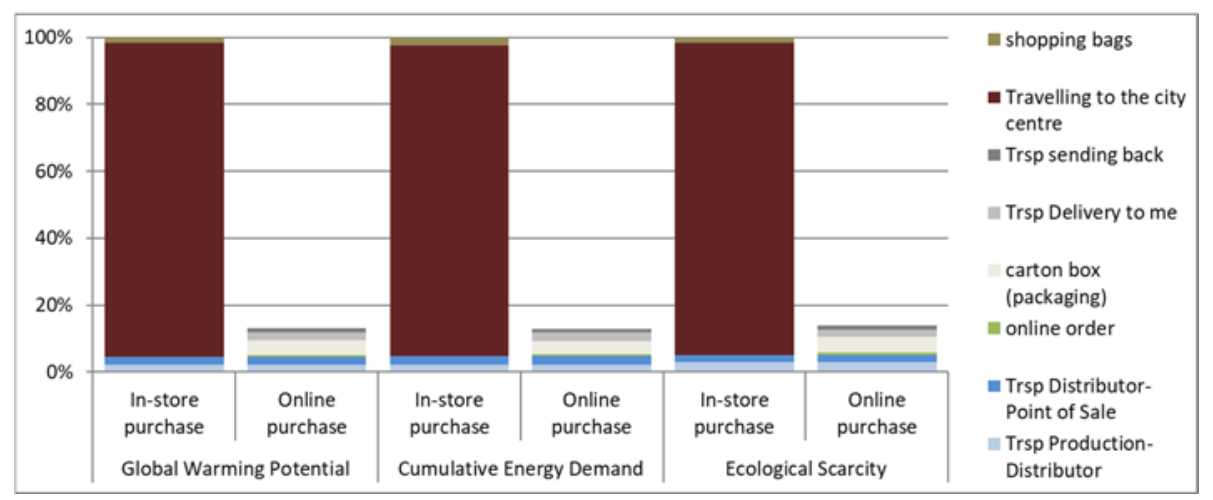

Figure 4. Comparison of the environmental impacts due to the shopping of clothes over one year for one person (i.e., total of 24 pieces) — either by travelling to the next city ("In-store purchase") or via the internet ("Online purchase").

The online purchase scenario shows an almost fourfold lower potential impact in all three of the LCIA impact categories considered; with the cause of most of this difference being the car travel to the city centre in the case of the traditional "shopping excursion" of the family; assuming that the car is occupied by a total of four persons and that besides all the clothes, further articles are acquired as well by these four persons. Therefore, only $75 \%$ of the potential impacts of this journey with the car are actually taken into account here. Nevertheless, all the carton boxes from the bi-monthly online orders 
still clearly show lower potential impacts than the three car trips to the city, as well as higher impacts than the "packaging material" of the shopping day (i.e., the various shopping bags).

\subsection{Sensitivity Analysis}

The two scenarios considered here (and summarised in Table 1) contain many variables that have been defined by using "reasonable" values that are considered sufficiently appropriate and representative of current behaviour and are thus suitable for obtaining a first general indication of performance. However, to gain a more coherent and comprehensive idea of the result, a perturbation analysis (a common type of sensitivity analysis) was performed in a further step. In this analysis, the influence of each variable was investigated individually in order to identify those variables that induce the greatest change in the overall potential impacts. Due to the fact that the overall number of purchased items is one of the investigated factors here, all the results for the cases of in-store purchase and online purchase, respectively, are this time related to one single clothes item that is purchased in order to continue to allow an unbiased and fair comparison between the two behaviour strategies. Tables 2 and 3 below summarize all the values of input variables that have been changed and/or have been investigated in the perturbation analysis. Additionally, we considered the potential impacts of antecedent information gathering about prospective goods by consumers via the internet (on the websites of the producing companies, as well as via social media platforms, in order to get advice and/or hints from other users), mainly to show its relevance in comparison to the other aspects covered in the two scenarios. As this activity is actually independent from the mode of purchase (i.e., in-store or online), this aspect has been added both times with the same two values, covering a time span from a quarter of an hour up to two hours (per single item).

Whilst in most cases, only the numerical values have been changing (e.g., $125 \mathrm{~km}$ of travelling instead of $85 \mathrm{~km}$ in the case of a "long" distance to the next city centre), there are two scenarios that resulted in a change of the used LCA data from ecoinvent:

- Scenario "Mean of transport for travelling to city" (see Table 2). To reduce the environmental impacts of the travel step, two different strategies can be followed: (i) changing the energy input of the applied mode of transport; or (ii) changing the mode of transport. For the latter, data for using a local train (i.e., the dataset "transport, passenger train, regional [CH]" from [21]) and for using a public bus (i.e., the dataset "market for transport, regular bus [GLO]") have been applied here, while for the first situation, an electric vehicle "fuelled" with the Swiss electricity grid is modelled (by combining the two datasets "market for transport, passenger car, electric [GLO]" and "market for electricity, low voltage $[\mathrm{CH}]$ ").

- Scenario "Packaging Material for Delivery" (see Table 3). An alternative to a carton box is the use of a plastic bag for the delivery of the ordered articles of clothing (used as alternative packaging material, e.g., by Zalando). For such a plastic bag, a weight of $12 \mathrm{~g}$ (representing $40 \%$ of the weight of a traditional plastic shopping bag) is assumed here.

Figure 5 shows the results per single clothes item for the various sensitivity cases of in-store purchase (defined in Table 2) for the impact category GWP (in $\mathrm{kg} \mathrm{CO}_{2}$-Eq.). This figure shows, in the left part, the additional impacts related to the gathering of information on the internet prior to the shopping trip (the green bars) that add around $16 \%$ to the total impact per clothing item if $2 \mathrm{~h}$ are spent by consumers on such research. The right part of this figure shows that each element related to the actual shopping trip that is varied has a relatively large influence on the result. The switch from travel to the next city via private car to the train results in a reduction in the overall potential impacts by a factor of around seven; after which, the mode of transport becomes about as relevant as the amount of shopping bags that are carried home. Taking a bus, or switching from a traditional petrol-fuelled car to an electric car, also reduced the overall potential impacts by a factor of about three; although the mode of transport remains a dominant factor. Another crucial variable was found to be distance travelled. Varying journey distance results in an almost proportional change in the overall potential 
impacts. Lastly, the number of purchased items per trip has an influence on the amount of potential impacts from transport that needs to be allocated to a single item of clothing. This is shown in the two scenarios varying the number of trips to purchase the same number of items (i.e., the scenarios " $2 \times$ per year" and " $6 \times$ per year"), as well as the two scenarios varying the total number of items purchased (i.e., scenarios "less" and "more"), respectively. Thus, the more items that are purchased in a single trip, the lower the transport effort that is required and a lower amount of transport-related potential impacts can be allocated to a single item of clothing.

Table 2. Applied upper and lower values in the sensitivity scenarios for the "in-store purchase" case (per single shopping time), including names of respective sensitivity scenarios in the figures below.

\begin{tabular}{|c|c|c|}
\hline & Upper Values & Lower Values \\
\hline Travelling distance to City centre & longer $(125$ km) & shorter $(45$ km) \\
\hline Number of annual trips to City centre & 6 times per year & 2 times per year \\
\hline Mean of transport for travelling to city & \multicolumn{2}{|c|}{ train/bus/electric vehicle } \\
\hline Number of purchased clothes (in one time) & more (16) & less $(4)$ \\
\hline Previous information gathering in Internet ${ }^{1}$ & long time (120 Min) & short time (15 Min) \\
\hline
\end{tabular}

${ }^{1}$ Done with a Laptop Computer.

Table 3. Applied upper and lower values in the sensitivity scenarios for the "online purchase" case (per single shopping time), including names of respective sensitivity scenarios in the figures below.

\begin{tabular}{|c|c|c|}
\hline & Upper Values & Lower Values \\
\hline Number of annual online orders & often (12) & few times (3) \\
\hline Previous information gathering in Internet ${ }^{1}$ & long time (120 min) & short time (15 min) \\
\hline Active ICT use time (per purchased item) & $\begin{array}{l}\text { long search (60 } \\
\text { min) }\end{array}$ & fast search (15 min) \\
\hline Used ICT device & \multicolumn{2}{|c|}{ tablet/smartphone } \\
\hline Number of purchased clothes (in one time) & more (11) & less (4) \\
\hline Number of cloths items that are send back & a lot back (6) & few back (2) \\
\hline Mean to bring parcel back to postal office & \multicolumn{2}{|c|}{ private car } \\
\hline Transport of "delivery to me" & from far $(770 \mathrm{~km})^{2}$ & from near $(350 \mathrm{~km})^{3}$ \\
\hline Packaging Material for Delivery & \multicolumn{2}{|c|}{ plastic envelope } \\
\hline
\end{tabular}

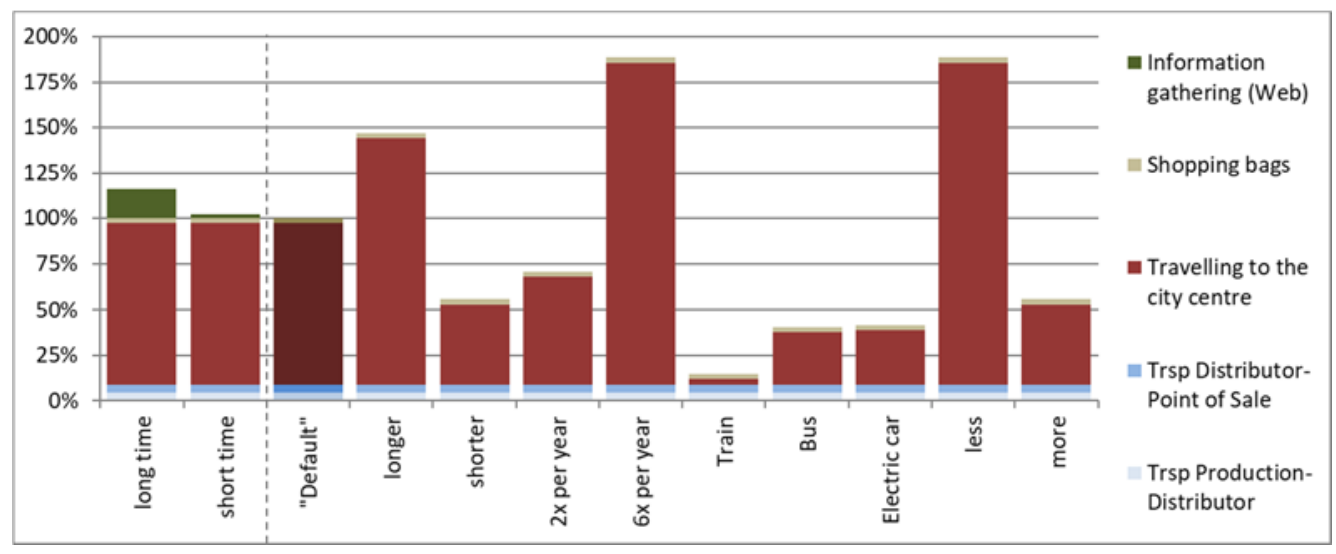

Figure 5. Comparison of the global warming potential (GWP) in $\mathrm{kg} \mathrm{CO}_{2}$-Eq of the purchase of one single clothing item when varying the various key assumptions in the case of an in-store purchase-the bar "default" represents the results of the basic scenario (data in Table 1). 
Figure 6 shows the GWP results (in $\mathrm{kg} \mathrm{CO}_{2}$-Eq) per single clothes item for the various sensitivity cases of an online purchase. In this case, all the additional impacts related to information gathering on the internet prior to online purchasing add more than $50 \%$ to the total impact per item of clothing if two additional hours are spent on the computer (see upper left part of the figure). It can also be seen in this upper part of the figure that all the variations in variable values related to the use of ICT devices for the actual order (i.e., the duration of the order and the device used) have a minimal influence on the overall result only. The most influential variable is the number of ordered items that are returned to the retailer (shown in the lower part of Figure 6); this is due to the fact that transport use and packaging requirements are ultimately distributed among the (few) items of clothing that are retained by the consumer, as this is the actual value that the user gets out of the entire online purchase activity.

Finally, another comparison between the two scenarios is performed, this time using the results from the default scenarios (shown above in Figure 4) and, in addition, the range of results from the two sensitivity scenarios showing the highest and the lowest resulting impacts (per single cloths item purchased-without the impacts related to any prior information gathering on the internet), respectively. The resulting comparison, again showing all three factors examined in this study, can be found in Figure 7. It is clearly visible from this figure that the variability in the total potential impacts for the traditional way of purchasing clothes (i.e., going to a city for an in-store purchase) is much higher than that in the case of online purchasing. This high variability is due to the considerable influence of transport distance and mode on the results of the former. Almost the entire range of the total potential impacts of the online shopping scenario is within that of the traditional in-store purchasing option.

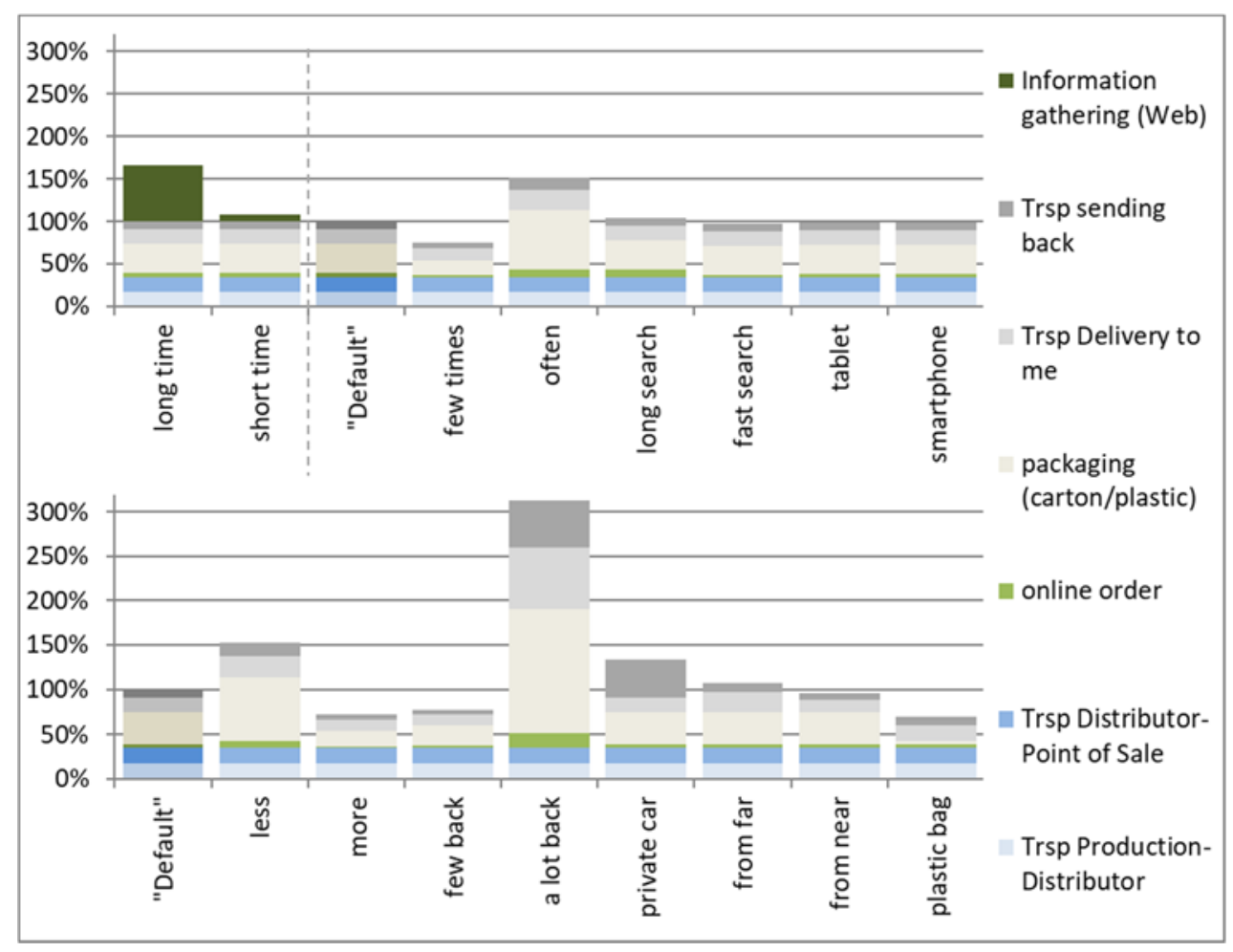

Figure 6. Comparison of the resulting global warming potential (GWP) in $\mathrm{kg} \mathrm{CO}_{2}$-Eq from the shopping of one single cloths item when varying the various key assumptions in the case of an online purchase on the internet-the bar "default" in both parts of the figure represents the results of the basic scenario (data in Table 1). 


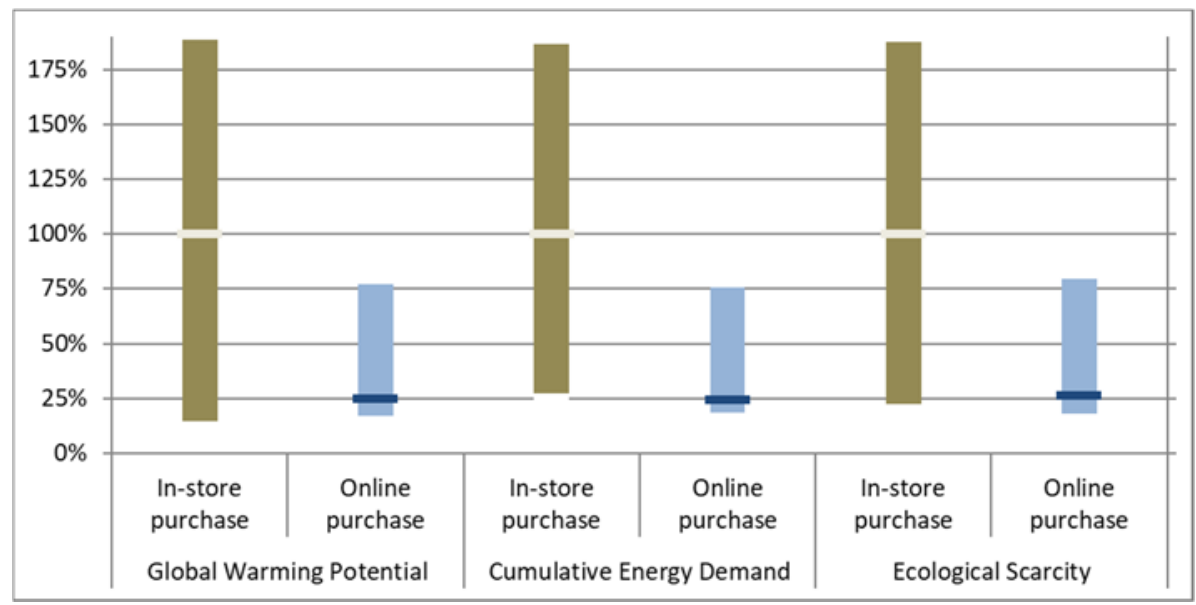

Figure 7. Comparison of the resulting ranges of the environmental impacts from the shopping of one single cloths item-either when travelling to the next city ("In-store purchase") or when doing the shopping on the internet ("Online purchase")—-when taking into account the full range of variability due to the here applied ranges for the different key parameters.

\section{Discussion}

This study has compared the environmental performance of two common types of consumer shopping behaviour: in-store purchase vs online purchase. The comparison is based on an example chosen by the author that is considered a reasonable representation of the situation in Switzerland and for the objective of this study, i.e., acquiring a first idea of how these different ways of purchasing compare from the perspective of environmental sustainability. Hence, no empirical data about the shopping behaviour of the average modern Swiss citizen was considered here; the collection of such data was considered out of scope. Instead, the influence of changes of a broad range of variables has been analysed in the frame of an extensive perturbation analysis, described in Section 3.4. This analysis allows for the identification of key factors that influence potential impacts and provides greater insights into performance than where only single values used. Ultimately, the action of purchasing clothes and the related behaviour is something very individual and is thus guided by the personal knowledge and volition of reducing one's (environmental) footprint.

The analysis here showed that the major environmental impacts of in-store purchasing are due to individual travel (i.e., the return journey to the city from home). These impacts are chiefly influenced by the distance travelled (a factor that cannot readily be changed by an individual), the frequency of shopping trips during the year, and, in particular, the choice of transport mode (i.e., private car or public transport). In brief, using the train —-the least polluting mean of transport (in Switzerland) —and going shopping only a few times per year, results in potential impacts (per purchased item of clothing) that are comparable to those of online purchasing.

Concerning an online purchase, the main impacts are due to the various transport steps along the supply chain-from the place of production to the customer's home-followed by the type of packaging material used, e.g., a cardboard box. As the functionality of an online purchase lies only within those (clothes) items that in the end are not sent back, the higher the number of returned items, the greater the overall potential impact of the final purchase. The use of ICT (i.e., end-user devices as well as internet infrastructure) for the actual order procedure is only a minor contributor to the overall impacts (i.e., only around 5\% to each of the here considered impact categories). However, as shown in the first column of Figure 6, an extensive internet search prior to the actual placement of an order can add substantial impacts (reaching more than $50 \%$ for GWP, when assuming $2 \mathrm{~h}$ of additional internet searching per item). However, such prior research is actually undertaken largely independently of the actual purchasing process and can therefore also be linked to in-store purchasing. Hence, it is not 
necessarily the means of purchase that makes a difference, but rather the way that a consumer behaves and the choices that go along with this.

As an alternative to pre-purchase, online research, items could be selected from, for instance, a printed catalogue and then ordered via telephone. Whilst this type of consumer behavior was not considered here, such behavior is certainly similar in nature to that of modern online purchasing, with the only tangible difference being the negligible impacts of ICT use on the part of online purchasing. A catalogue is not per se a medium that results in lower impacts compared to a modern ICT infrastructure—as shown in the past years by different studies and authors [24-28]. This study did not take into account the fact that online shopping could potentially lead to increased consumption patterns of individuals overall, i.e., individuals may purchase many more items of clothing over a year than they would when they have to purchase goods exclusively in-store at the nearest city.

In conclusion, there does not appear to be an environmental advantage by default to purchasing items of clothing online compared with purchasing those same items in-store at the nearest city. Rather, it all depends on the behaviour of the individual consumer and the choices they make. In both cases, minimising or optimising all transport activities as much as possible is key for achieving an environmentally friendly shopping experience. For instance, such reductions can be achieved by using public transport for in-store purchases or by reducing the annual frequency of online orders and returns.

Supplementary Materials: The following are available online at http:/ /www.mdpi.com/2071-1050/10/9/3061/ s1, giving a more detailed overview of the assumptions and Life Cycle Inventory data for the two basic scenarios.

Funding: This research received no external funding.

Acknowledgments: The author would like to say "thank you" to the Swiss Packaging Industry Association (i.e., SVI, Schweizerisches Verpackungsinstitut) for initiating this activity and for allowing the presentation of the results during the annual industry exhibition event in Zürich (April 2018). Further thanks goes to David Turner from my research group here at Empa for his critical review and English proofreading.

Conflicts of Interest: The author declares no conflict of interest.

\section{References}

1. Zalando. Protect-Environment |Zalando Corporate. Available online: https:/ /corporate.zalando.com/en/ corporate-responsibility / environment-important-us-how-we-are-getting-involved (accessed on 30 May 2018).

2. H\&M Group. HEM Group Sustainability Report 2017; H\&M: Stockholm, Sweden, 2018.

3. World Commission on Environment and Development (WCED). Our Common Future; Oxford Press: Oxford, UK, 1987.

4. Ness, B.; Urbel-Piirsalu, E.; Anderberg, S.; Olsson, L. Categorising tools for sustainability assessment. Ecol. Econ. 2007, 60, 498-508. [CrossRef]

5. Hendrickson, C.T.; Lave, L.B.; Matthews, H.S. Environmental Life Cycle Assessment of Goods and Services: An Input-Output Approach, 1st ed.; Routledge: New York, NY, USA, 2006.

6. Borggren, C.; Moberg, A.; Finnveden, G. Books from an environmental perspective-part 1: Environmental impacts of paper books sold in traditional and internet bookshops. Int. J. Life Cycle Assess. 2011, 16, 138-147. [CrossRef]

7. Weber, C.L.; Koomey, J.G.; Matthews, H.S. The energy and climate change implications of different music delivery methods. J. Ind. Ecol. 2010, 14, 754-776. [CrossRef]

8. Edwards, J.B.; McKinnon, A.C.; Cullinane, S.L. Comparative analysis of the carbon footprints of conventional and online retailing: A "last mile" perspective. Int. J. Phys. Distrib. Logist. Manag. 2010, 40, 103-123. [CrossRef]

9. Smidfelt Rosqvist, L.; Winslott Hiselius, L. Online shopping habits and the potential for reductions in carbon dioxide emissions from passenger transport. J. Clean. Prod. 2016, 131, 163-169. [CrossRef]

10. Van Loon, P.; Deketele, L.; Dewaele, J.; McKinnon, A.; Rutherford, C. A comparative analysis of carbon emissions from online retailing of fast moving consumer goods. J. Clean. Prod. 2015, 106, 478-486. [CrossRef]

11. Yi, Y.; Wang, Z.; Wennersten, R.; Sun, Q. Energy Procedia. In Life Cycle Assessment of Delivery Packages in China; Elsevier: New York, NY, USA, 2017; pp. 3711-3719. 
12. Weideli, D. Environmental Analysis of Us Online Shopping; Ecole Polytechnique Fédérale de Lausanne-EPFL: Lausanne, Switzerland, 2013.

13. Subramanian, K.; Yung, W.K.C. Review of life cycle assessment on consumer electronic products: Developments and the way ahead. Crit. Rev. Environ. Sci. Technol. 2016, 46, 1441-1497. [CrossRef]

14. Pihkola, H.; Hongisto, M.; Apilo, O.; Lasanen, M. Evaluating the energy consumption of mobile data transfer-From technology development to consumer behaviour and life cycle thinking. Sustainability 2018, 10, 16. [CrossRef]

15. Coroama, V.; Hilty, L.M.; Heiri, E.; Horn, F. The direct energy demand of internet data flows. J. Ind. Ecol. 2013, 17, 680-688. [CrossRef]

16. Hischier, R.; Coroama, V.C.; Schien, D.; Achachlouei, M.A. Grey energy and environmental impacts of ICT hardware. In ICT Innovations for Sustainability; Hilty, L.M., Aebischer, B., Eds.; Springer: Cham, Switzerland, 2015.

17. Malmodin, J.; Lundén, D.; Moberg, A.; Andersson, G.; Nilsson, M. Life cycle assessment of ICT: Carbon footprint and operational electricity use from the operator, national, and subscriber perspective in sweden. J. Ind. Ecol. 2014, 18, 829-845. [CrossRef]

18. Palos-Sanchez, P.; Saura, J.R. The effect of internet searches on afforestation: The case of a green search engine. Forests 2018, 9, 24. [CrossRef]

19. Statista.com. Online-Shopping and E-Commerce Worldwide: Statistics \& Facts. Available online: https:/ / www.statista.com/topics/871/online-shopping/ (accessed on 10 August 2018).

20. Kessler, P.; Hochreutener, T. Online-und Versandhandelsmarkt Schweiz 2017; GFK: Zürich, Switzerland, 2018.

21. Ecoinvent Centre. Ecoinvent Data v3.4-Recycled-Content System Model-Available at www.ecoinvent.org; Ecoinvent Association: Zürich, Switzerland, 2017.

22. Bourgault, G. Implementation of IPCC Impact Assessment Method 2007 and 2013 to Ecoinvent Database 3.2; Ecoinvent Association: Zürich, Switzerland, 2015.

23. Frischknecht, R.; Büsser Knöpfel, S. Kofaktoren Schweiz 2013 Gemäss der Methode der Ökologischen Knappheit. Methodische Grundlagen und Anwendung auf Die Schweiz; Bundesamt für Umwelt (Bafu): Bern, Switzerland, 2013; p. 256.

24. Achachlouei, M.A.; Moberg, A. Life cycle assessment of a magazine-Part 2: A comparison of print and tablet editions. J. Ind. Ecol. 2015, 19, 590-606. [CrossRef]

25. Moberg, A.; Borggren, C.; Finnveden, G. Books from an environmental perspective-Part 2: E-books as an alternative to paper books. Int. J. LCA 2011, 16, 238-246. [CrossRef]

26. Moberg, A.; Johansson, M.; Finnveden, G.; Jonsson, A. Printed and tablet E-paper newspaper from an environmental perspective-A screening life cycle assessment. Environ. Impact Assess. Rev. 2010, 30, 177-191. [CrossRef]

27. Hischier, R.; Reichart, I. Multifunctional electronic media-Traditional media. The problem of an adequate functional unit-A case study of a printed newspaper, an internet newspaper and a TV broadcast. Int. J. LCA 2003, 8, 201-208. [CrossRef]

28. Hischier, R.; Keller, M.; Lisibach, R.; Hilty, L.M. Proceedings of the First International Conference on Information and Communication Technologies for Sustainability, ETH Zürich, 2013. In Mat—An ICT Application to Support a More Sustainable Use of Print Products and ICT Devices; Hilty, L.M., Aebischer, B., Andersson, G., Lohmann, W., Eds.; ICT4S: Zürich, Switzerland, 2013; pp. 223-230.

(C) 2018 by the author. Licensee MDPI, Basel, Switzerland. This article is an open access article distributed under the terms and conditions of the Creative Commons Attribution (CC BY) license (http://creativecommons.org/licenses/by/4.0/). 